\title{
PRODUÇÃO ARTESANAL DA PASTA DE SOJA MISSÔ
}

\section{ARTISAN PRODUCTION OF SOYBEAN PASTE MISSO}

\author{
Caroline Tiemi Yamaguishi ${ }^{1}$; José Luiz. Ferreira da Trindade ${ }^{2}$ \\ ${ }^{1}$ Universidade Tecnológica Federal do Paraná - UTFPR - Ponta Grossa - Brasil \\ carolineyamaguishi@terra.com.br \\ ${ }^{2}$ Universidade Tecnológica Federal do Paraná - UTFPR - Ponta Grossa - Brasil \\ trindade@pg.cefetpr.br
}

\begin{abstract}
Resumo
O presente trabalho procurou resgatar a tecnologia artesanal da produção da pasta de soja, missô, visto que essa tecnologia está se perdendo mesmo entre os imigrantes japoneses e seus descendentes. Foram comparadas as técnicas utilizadas para a elaboração do missô artesanal e dos missôs que são produzidos comercialmente. As análises físico-químicas, avaliando o teor de umidade, proteína, lipídios e $\mathrm{pH}$, mostraram pequenas variações nos valores encontrados, sendo que a perda nutritiva foi considerada baixa nesse processo. Também foram realizadas análises microbiológicas do missô artesanal, comprovando que é um alimento seguro e que pode ser ingerido sem apresentar danos à saúde.
\end{abstract}

Palavras-chave: soja; propriedades funcionais; tecnologia; missô artesanal; missôs comerciais.

\section{Introdução}

Atualmente a soja é consumida em todo o mundo sob as mais variadas formas, sendo ainda, muito utilizada na culinária japonesa. Os pratos e ingredientes de origem japonesa são altamente valorizados não apenas pelo valor nutritivo, mas também por seus significados simbólicos. Tais alimentos vêm proporcionando uma melhor qualidade de vida e uma maior longevidade.

As propriedades benéficas do uso da soja vêm sendo muito discutidas, podendo ser comprovadas pela vitalidade das mulheres japonesas, que têm menor incidência de doenças se comparada às mulheres ocidentais devido ao consumo da soja e seus derivados (ISOGAWA, 2004).

O trabalho realizado consistiu no preparo da pasta de soja, missô, na cidade de Balsa Nova PR no período de novembro/2003 a agosto/2004, onde se procedeu, um acompanhamento mensal nos oito meses de fermentação do produto. 


\subsection{Pasta de soja - missô}

O nome científico da soja é Glycine $\max$ (L.) Merr., e ela pertence à família Fabaceae de leguminosas, existem mais de 2.500 variedades de soja. Composta aproximadamente por $40 \%$ de proteína, $20 \%$ de óleo e gorduras, $17 \%$ de celulose e hemicelulose, $7 \%$ de açúcares e $6 \%$ de minerais. Além desses componentes, ela contém ainda significativa quantidade de fitohormônios ou estrógenos naturais (denominadas isoflavonas). Substâncias fisiologicamente ativas que atuam como moduladores de processos metabólicos, na melhoria do bem estar e que ajudam na prevenção de doenças degenerativas (GORZONI, 2002).

O missô é um alimento preparado pela fermentação de soja e sal com ou sem arroz em proporções que variam de acordo com o tipo desejado. A soja faz parte das fermentações de vegetais que se tornaram complexas e exigem a preparação prévia de enzimas, que no caso da soja é denominado koji.

Para a fabricação do missô é necessário preparar, primeiramente, o koji. A fabricação do missô envolve duas fases: a primeira, onde o koji é preparado por ação do fungo sobre o arroz polido ou cevada; e a segunda, onde a soja é fermentada por ação do koji (enzimas) (CAMARGO et al, 1984).

No processo de fermentação do missô as enzimas produzidas no koji se encarregam de digerir os componentes do arroz e da soja; sendo o amido do arroz digerido pela amilase e maltase à dextrina, maltose e glucose, e a proteína de soja digerida pelas proteases a peptídeos e aminoácidos. Também o óleo contido na soja é digerido, pelas lipases a ácidos graxos (CARRENO, 1990).

\section{Material e Métodos}

\subsection{Material para a elaboração da pasta de soja fermentada}

Arroz branco (tipo japonês), koji congelado, soja em grãos, sal.

\subsection{Métodos}

Elaboração do Missô Artesanal: 1) Preparo do koji (seleção e hidratação de 18,7 kg de arroz por 24 horas; cozimento a vapor em fogão a lenha por 40 a 45 minutos; resfriamento; mistura de 0,5 $\mathrm{Kg}$ de koji de arroz congelado; cobre-se com panos e cobertores por 4 a 5 dias; retira os panos e cobertores e deixa à temperatura ambiente por 24 horas). 2) Preparo do missô (seleção e hidratação 26 kg de soja por 24 horas; cozimento em água por 12 horas; resfriamento por 10 horas; separação 
dos grãos de soja do caldo resultante do cozimento; amassamento dos grãos de soja cozidos em pilão de madeira; resfriamento da massa à temperatura ambiente por aproximadamente 30 minutos; mistura de $18 \mathrm{Kg}$ do caldo resultante do cozimento, $14 \mathrm{Kg}$ de sal e 19,2 Kg de koji; armazenamento em tambor de plástico).

Foram realizadas análises físico-químicas do missô artesanal com a finalidade de monitorar as alterações no $\mathrm{pH}$, umidade, proteína e lipídios. As amostras foram coletadas no 1o, 4o e 8o mês de fermentação, que correspondem ao início, meio e final do tempo de acompanhamento que foi de oito meses. Análises Físico-Químicas: Determinação da umidade: método de perda por dessecação (Aquecimento Direto); determinação de proteínas: método de Digestão de Kjeldahl; determinação de lipídios: método de Extração de Soxhlet; determinação do pH: Método da Determinação Eletrométrica do $\mathrm{pH}$ segundo as normas do Instituto Adolfo Lutz.Todas as análises foram realizadas em triplicata.

As análises microbiológicas foram feitas utilizando-se uma amostra do missô artesanal no 5o mês de fermentação. Análises Microbiológicas: Contagem de Staphylococcus aureus em placas; Contagem de Coliformes a 45oC; Pesquisa de Salmonella sp segundo as técnicas do Instituto de Tecnologia de Alimentos (ITAL). Todas as análises foram realizadas em triplicata.

\section{Resultados e discussão}

O produto não apresentou uniformidade na sua aparência, ficando alguns grãos partidos na massa decorrente do esmagamento da soja no pilão, contrastando com o esmagamento mecânico feito em escala comercial.

Quanto a porcentagem de sal, foi verificado que o missô artesanal apresentou um teor de $12,92 \%$, valor que se aproxima do encontrado no "Sendai missô", que é de 12,8\% segundo SHIBASAKI; HESSELTINE (1962 apud MENEZES, 19-).

\subsection{Análises físico-químicas}

Os resultados de cada análise estão representados no Tabela 1 a seguir:

Tabela 1 - Resultados das análises físico-químicas

\begin{tabular}{|c|c|c|c|c|c|}
\hline \multirow{2}{*}{$\begin{array}{c}\text { Tempo de } \\
\text { fermentação } \\
\text { (meses) }\end{array}$} & \multirow{2}{*}{$\begin{array}{c}\text { Umidade } \\
(\%)\end{array}$} & \multicolumn{2}{|c|}{ Proteína } & \multirow{2}{*}{$\begin{array}{l}\text { Lipídios } \\
\text { (\%) }\end{array}$} & \multirow[t]{2}{*}{ pH } \\
\hline & & $\begin{array}{c}\text { Base úmida } \\
(\%) \%\end{array}$ & Base seca $(\%)$ & & \\
\hline 1 & 52,31 & 8,39 & 17,59 & 2,70 & 4,96 \\
\hline 4 & 56,76 & 9,29 & 21,48 & 2,50 & 5,03 \\
\hline 8 & 52,72 & 8,78 & 18,57 & 1,00 & 4,95 \\
\hline
\end{tabular}


As diferenças nos valores encontradas para a umidade, podem ser justificadas, pelo método de moagem utilizado, socado em pilão de madeira, obtendo-se uma mistura heterogênea (massa e grãos partidos).

Se comparado ao Sendai missô (50,1 \% de umidade) (SHIBASAKI; HESSELTINE, 1962 apud MENEZES, 19-) que serve de referência por ser o que mais se aproxima dos missôs produzidos no Brasil, o teor de umidade é maior. Isso pode ser justificado pelo fato de, no missô artesanal ser adicionado o caldo (resultante do cozimento da soja) e nos missôs comerciais este caldo ser descartado.

Os valores encontrados para o teor de proteína, lipídios e $\mathrm{pH}$, foram muito próximos ao citados por SHIBASAKI; HESSELTINE (1962) apud MENEZES (19-).

As porcentagens obtidas para o teor de proteína podem estar relacionadas ao teor de proteína da variedade de soja utilizada. Quanto maior for o teor proteico da soja, maior será o teor proteico do missô, lembrando que as perdas nas outras etapas devem ser mínimas.

A pasta inicial apresentava $2,7 \%$ de lipídios e terminou com $1,0 \%$, mostrando uma queda acentuada no teor de lipídios, provavelmente, utilizado como fonte energética pelos microorganismos presentes no meio.

\subsection{Análises microbiológicas}

A fim de constatar a inocuidade da pasta de soja artesanal foram realizadas as análises microbiológicas exigidas pela legislação para este tipo de produto. Os resultados obtidos de cada análise estão representados no Tabela 2:

Tabela 2 - Resultados das análises microbiológicas

\begin{tabular}{|c|c|c|}
\hline Análises & Resultados & $\begin{array}{c}\text { Padrão microb. Segundo } \\
\text { RDC 12/2001 MS }\end{array}$ \\
\hline $\begin{array}{c}\text { Contagem de Staphylococcus } \\
\text { aureus }\end{array}$ & $<10,0 \mathrm{UFC} / \mathrm{g}$ & $10^{2} \mathrm{UFC} / \mathrm{g}$ \\
\hline Contagem de Coliformes a 45oC & $<10,0 \mathrm{UFC} / \mathrm{g}$ & $10^{2} \mathrm{UFC} / \mathrm{g}$ \\
\hline Pesquisa de Salmonella sp & Ausência em $25 \mathrm{~g}$ & Ausência em $25 \mathrm{~g}$ \\
\hline
\end{tabular}

${ }^{1}$ Nota: Os valores apresentados estão em $\mathrm{g} / 100 \mathrm{~g}$ da amostra.

De acordo com os valores encontrados o missô artesanal foi considerado ALIMENTO PRÓPRIO PARA O CONSUMO. 


\title{
4. Conclusão
}

Percebeu-se que, apesar de se tratar de um produto artesanal, o produto é seguro quanto à qualidade microbiológica. Isso pode ser explicado pelo fato de o inóculo utilizado (A. oryzae) não permitir o desenvolvimento de microrganismos patógenos. A qualidade nutricional desse tipo de produto é também considerada satisfatória visto que os resultados das análises físico-químicas estão próximos dos encontrados na literatura.

A vantagem de consumir o missô é o alto valor biológico desse produto, pois, devido ao processo de fermentação as moléculas de proteínas são quebradas em moléculas mais simples que facilitam a digestibilidade da soja. Conclui-se, portanto, que tanto a pasta de soja fermentada comercial quanto a artesanal podem ser consumidas com segurança.

\begin{abstract}
The present work ransomed the artisan technology of the soybean paste production, misso, being aware that this technology is being lost even among the Japanese Immigrants and their descendings. The technics used for the elaboration of the artisan misso was compared to the commercially produced missos. Through a sensorial analysis (Quantitive Descriptive Analysis) it was possible to confirm that the artisan misso has different characteristics of the commercial missos, having good acception of its attributes and presenting greater diversity of aromas and tastes. The physicalchemical analysis evaluating the percentage of moisture, protein, oils and $\mathrm{pH}$, showed small variations in the found values, even a nutricious loss was considered low in that process. The microbiology analysis of this artisan misso was also performed, confirming it as a safe food and can be ingested without presenting damages to health.
\end{abstract}

Key-words: soybean; funcional proprieties; technology; artisan misso; commercial missos.

\section{Referências}

CAMARGO, R. de. et al. Alimentos tradicionais, in: Paulo: Nobel, 1984, p. 272-273. Tecnologia de produtos agropecuários-alimentos. São

CARRENO, R. E. S. de. Aproveitamento de matérias-primas alternativas para a pasta de soja fermentada "miso". Curitiba, 1990, 116 folhas. Tese de Mestrado em Tecnologia Química - Setor de Tecnologia, Universidade Federal do Paraná.

CENTRO FEDERAL DE EDUCAÇÃO TECNOLÓGICA DO PARANÁ. Unidade de Ponta Grossa. Laboratório de Métodos Instrumentais e Laboratório de Microbiologia.

GORZONI, P. Os grãos dourados. Óleos e Grãos, São Paulo, ano X, no 67, p. 12-17, jul / ago 2002.

HESSELTINE, C. H.; WANG, H. L. Fermented soybean food productos. In: SMITH, A. K.; CIRCLE, S. J. Chemistry and Technology. Tradução: Caroline Tiemi Yamaguishi. Westport, Avi: Soybean, 1972, v. 1, p.389-419.

INSTITUTO ADOLFO LUTZ. Normas analíticas do Instituto Adolfo Lutz: métodos químicos e físicos para análise de alimentos. 3 ed. São Paulo, 1985, v. 1, p. 21-22,26-27, 42-45. 
ISOGAWA, M. S. Propriedades da soja, disponível em <http: // www.nippobrasil.com.br/2.semanal.saude /224.shtml $>$, acesso em 18/03/2004.

MENEZES, T. J. B. Alimentos tradicionais do Oriente à base de soja, in: CASTRO, L. A. Soja: utilização e aspectos tecnológicos. [S.I.: s.n.], [19-], p. 902-903, 908.

\section{Primeiro autor:}

Nome completo: Caroline Tiemi Yamaguishi

Filiação institucional: Universidade Tecnológica Federal do Paraná - Ponta Grossa/PR

Função ou cargo ocupado: Tecnologia em Alimentos - Industrialização de Lacticínios

Endereço completo para correspondência: Rua Konrad Kuno Frank, casa 138 bairro: Xaxim

CEP: 81720-380 Curitiba -PR Brasil

Telefones para contato: (41) 3275-7185 ou (41) 9946-0382

e-mail: carolineyamaguishi@terra.com.br 